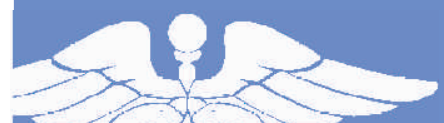

ISSN: 2782-7550 (Print) SSN: 2782-7542 (Online)

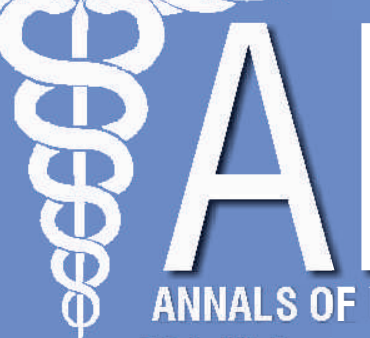

(4) ANNALS OF BASIC AND MEDICAL SCIENCES A Scientific Peer Reviewed Publication of The Faculties of Basic Medical and Basic Clinical Sciences,Usmanu Danfodiyo University Sokoto, Nigeria
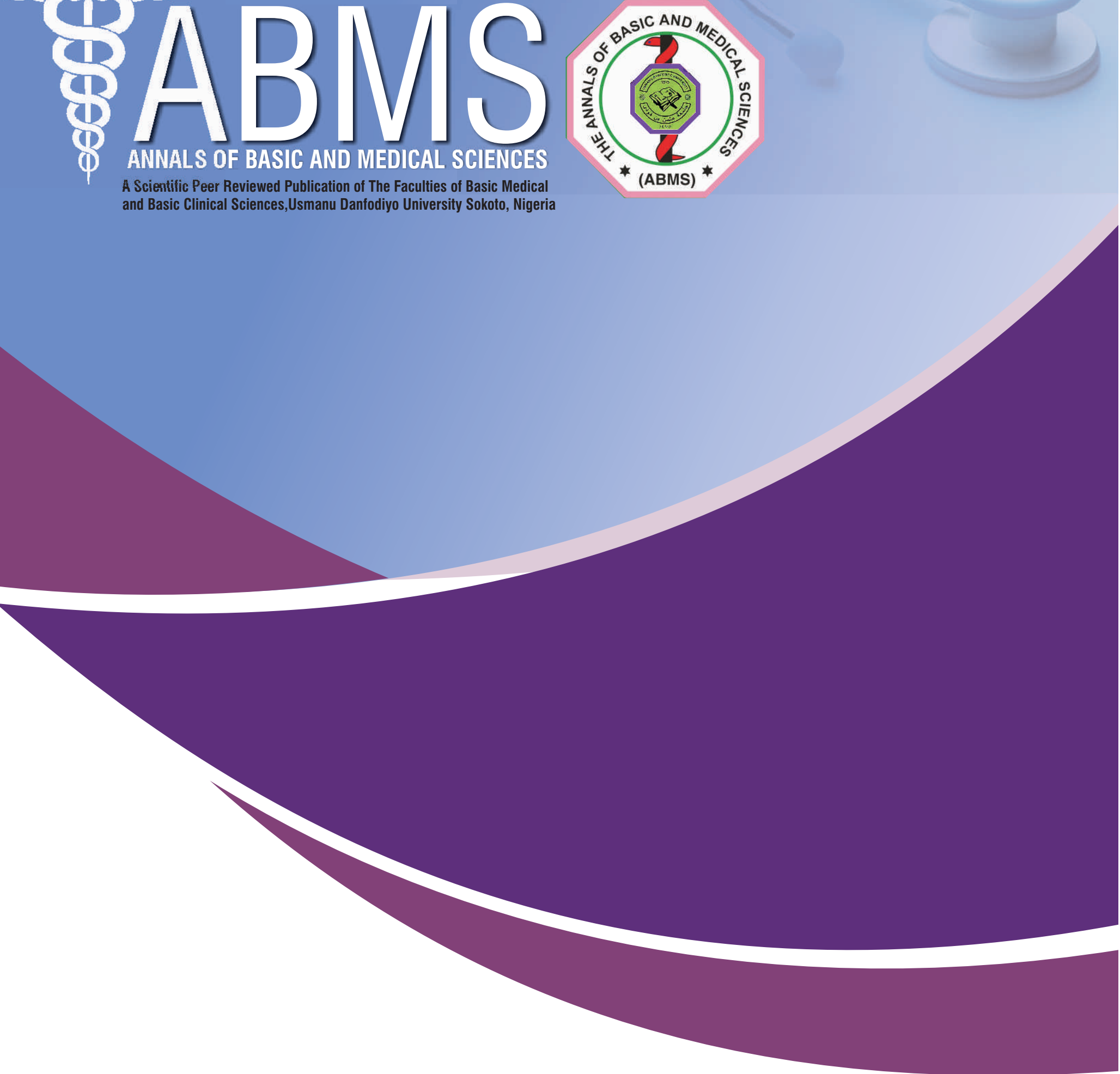

(ABMS) ${ }^{*}$ 


\title{
Toxoplasmosis among Pregnant Women in Africa: A Systematic Review and Meta-Analysis
}

\author{
Sharif A. Abdullahi', Hassan Yahaya ${ }^{2}$, Ja'afaru S. Mohammed ${ }^{3}$ \\ 'Department of Medical Microbiology and Parasitology, Faculty of Clinical Sciences, Bayero University Kano, Nigeria \\ ${ }^{2}$ Department of Medical Laboratory Sciences, Faculty of Allied health Sciences, Bayero University Kano, Nigeria \\ ${ }^{3}$ Department of Biochemistry, Faculty of Science, Kaduna State University, Kaduna State, Nigeria
}

\begin{abstract}
Toxoplasmosis in pregnancy may have serious consequences on the pregnancy outcome. Vertical transmission to the fetus may range from obstetrics complications such as abortion, intrauterine growth restriction, stillbirth to congenital malformations. This review aimed to assess the seroprevalence rate of toxoplasmosis in pregnant women in Africa so that a proper management policy can be initiated. Four databases that include Google Scholar, ScienceDirect, Scopus, and PubMed were searched for primary studies reported on the prevalence of toxoplasmosis among pregnant women in African countries. From the search, total of 39 studies were included for the study from 1980 to 2018. Total of 11986 pregnant women were the study participants in the included studies. By using the DerSimonian-Liard random effects method, the pooled prevalence of toxoplasmosis was estimated as $47 \%(95 \% \mathrm{Cl}=38.4 \%$ to $55.4 \%)$. Publication bias was assessed using Egger's test, $2.88(95 \% \mathrm{Cl}=-8.8 \%$ to $14.5 \%)$ and it did not indicate any significant $(P=0.619)$ influence of the studies on the pool estimate. Again, the pooled estimates of toxoplasmosis among pregnant women in first, second and third trimesters were $29 \%$ $(95 \% \mathrm{Cl}=17.0 \%$ to $42.0 \%), 35.0 \%(95 \% \mathrm{Cl}=27 \%-43 \%)$ and $30.9 \%(95 \% \mathrm{Cl}=22 \%-41 \%)$, respectively. Pooled prevalence for risk factors such as 'contacts with cat', cat ownership and consumption of raw or poorly cooked meat were estimated at $50 \%(95 \% \mathrm{Cl}=35 \%$ to $66 \%$ ), $26.2 \%$ $(95 \% \mathrm{Cl}=17.9 \%$ to $35.5 \%)$ and $43.3 \%(95 \% \mathrm{Cl}=30 \%$ to $50 \%)$ respectively. This study estimates the overall prevalence of toxoplasmosis in pregnancy and some possible risk factors through which majority of pregnant women can be infected. Proper screening against this infection should be instituted in full capacity to curb the endemicity and consequences of the infection on the fetus.
\end{abstract}

Keywords: Toxoplasmosis, Pregnancy, Africa, Systematic review, Meta-analysis

Corresponding author:

Sharif Alhassan Abdullahi,

Department of Medical Microbiology and Parasitology, Faculty of Clinical Sciences,

Bayero University Kano, Nigeria Email: asabdullahi.mcp@buk.edu.ng

\section{Introduction}

$\mathbf{T}$ oxoplasma gondii is widely spread zoonotic protozoan parasite that causes toxoplasmosis in human with varying degree of severity depending on the immune status of individual. Toxoplasmosis has a global distribution with variation in parasite genotype and or strain in circulation within the community. Up to date, between 30 to $65 \%$ of the world population were reported to be affected, though most of them do not show any sign of the disease but its presence constitutes a serious hazard on the health of the individuals (1). Africa is another region worst hit by toxoplasmosis due to its climatic factors and environmental conditions that significantly play a role in the continuous transmission of the parasite. For the past decade, high prevalence of toxoplasmosis was recorded among pregnant women, children, HIV-positive subjects and the general population. However, like other regions, the prevalence also shows a different pattern between the subjects and between and within countries (2). Human and other warmblooded animals as well as birds are intermediate hosts to $T$. gondii while the feline cats are the definitive hosts.

T. gondii has three parasitic stages that include a rapidly dividing invasive tachyzoite, slowly dividing bradyzoite within a tissue cyst and the sporozoite protected within an oocyst floating in the environment with the potential of contaminating most of the vehicles of transmission such as water, soil, vegetable and fruits (2). The sporulated oocyst is transmitted through contaminated food, water, vegetable, and fruits. The rapidly replicating tachyzoite within the nucleated cells converts to a slowly replicating bradyzoite stage embedded within the deep tissues of the brain, heart muscles, skeletal muscles, retina, and placenta to form a tissue cyst. Therefore, bradyzoite can be transmitted through ingestion of tissue cyst contaminated meat and through placenta to a fetus in-utero and occasionally through organ transplant or blood transfusion (3). Pregnant women are among the high risk groups $(4,5)$ and they can acquire infection through sporulated oocyst due to environmental exposure to soil, consumption of contaminated water, vegetable or fruit and through ingestion of poorly cooked or raw contaminated meat. Depending on the gestational age, immune system and the time frame of the infection, transmission of the replicating tachyzoite through the placenta to the growing fetus occurs with varying degree of consequences (6). Primary infection in a woman while pregnant, within the first or 
second-trimester, results in spontaneous abortion, intrauterine growth restriction or stillbirth $(3,7)$ whereas, infection in the third-trimester results in delivery of the normal baby. This is because at an early stage of pregnancy, the transmission of tachyzoites through the placenta in primary infection is less likely, but if it occurs, it is associated with a varying degree of clinical consequences whereas the rate of transmission in the third trimester is over $60.0 \%$ (8). This is probably due to strong immune control by the placenta at the early stage of the pregnancy (9).

Infection acquired before conception is not likely to be transmitted to the fetus but vertical transmission can occur in immunocompromised women with chronic T. gondii infection, but its prevalence was reported to be low especially if it is being managed with Spiramycin (8). Apart from obstetrics complications and congenital abnormalities that can manifest in the neonate, many congenitally infected newborns are likely to develop severe illnesses such as retinochoroiditis, blindness and mental disorders later in life.

Although, many studies reported the prevalence of toxoplasmosis among pregnant women in various parts of Africa, the current review aims at determining the weighted prevalence in African sub-population of pregnant women in view of possible action by authorities to intensify campaign on preventive measures to minimize mother-to-child transmission and proper management of congenital toxoplasmosis.

\section{Methods}

\subsection{Search strategy}

This systematic review and meta-analysis were designed to evaluate the prevalence of toxoplasmosis among pregnant women in Africa. This study was reported according to the Preferred Reporting Items for Systematic review and Meta-Analyses (PRISMA) guidelines (Figure 1). Published articles that are available online and reported in English were searched from four prominent databases Google Scholar, Science Direct, Scopus, and PubMed. The search identified studies that were published on the prevalence of toxoplasmosis among pregnant women from January 1980 to December 2018. The literature was searched using medical subject headings (MeSH) terms such as "Prevalence", "Seroprevalence", "Toxoplasma gondii", "T. gondii" "toxoplasmosis", "pregnancy", Pregnant women", "Antenatal women", "Africa". The terms were used in combination using Boolian operators such as "AND" and "OR".

\subsection{Study selection}

Published cross-sectional studies based on serological detection of anti-toxoplasma gondii antibodies among pregnant women in Africa were included in this review. All the included articles were reported in English and that contain information about study area and subjects,

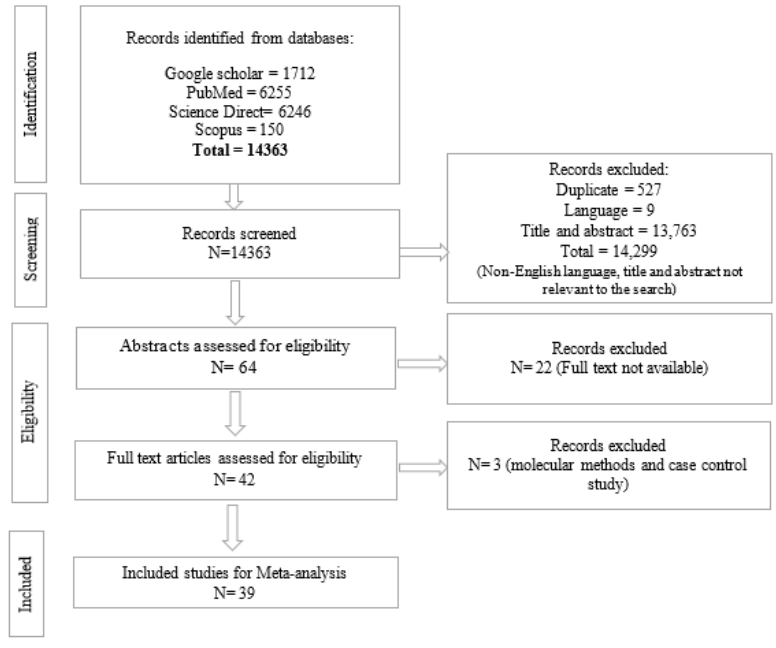

Figure 1. Flow chart describing the study processes

sample size, prevalence of toxoplasmosis among pregnant women during antenatal period in different parts of Africa. The searched articles were screened for title and abstract. The full text articles available in literature were considered for eligibility assessment. Out of the 42 full text articles assessed for eligibility, 39 were considered for the review and meta-analysis (Figure 1). The quality of the eligible primary studies (Table 1) was assessed using the Newcastle quality assessment checklist for cross-sectional study (9). The authors discussed and resolved all discrepancies on the exercise.

\subsection{Data extraction}

All articles assessed for inclusion were studied. Article information such as authors name, publication year, study design, period of the study, sample size, number of participants, prevalence of toxoplasmosis, diagnostic method and country of the study were extracted carefully using Microsoft excel. Data was collected on risk factors for toxoplasmosis such as cat ownership, contact with cats, consumption of raw or poorly cooked meat, consumption of vegetables, source of water and residence of the subjects. Available data on complications such as abortion and stillbirth were collected in this study.

\subsection{Statistical analysis}

Data from all eligible primary studies were entered into Microsoft Excel then exported into the trial version of StatsDirect statistical software (www.statsdirect.com) to compute the point estimate for each included study. The Forest plot was used to estimate the effect size and confidence interval $(\mathrm{Cl})$ for the primary studies and the total seroprevalence. Indices of heterogeneity $\left(I^{2}\right.$ and Cochrane Q statistics, $\mathrm{p}$-value $\left.<0.05\right)$ were used to assess the heterogeneity between the studies. Publication bias was evaluated using Egger's tests. 
Table 1: Assessment of study bias based on Newcastle Ottawa Scale; Maximum score is 5

$$
\text { Study country Selection comparability }
$$

\begin{tabular}{|c|c|c|c|c|c|c|c|c|}
\hline & & & Sample Representativene & Sample size & Diagnostic Procedure & Study design & Prevalence & $5(+)$ \\
\hline 1. & (7) & Ethiopia & + & + & + & + & + & 5 \\
\hline 2. & (11) & Ethiopia & + & + & + & + & + & 5 \\
\hline 3. & (12) & Ethiopia & + & + & + & + & + & 5 \\
\hline 4. & (13) & B/Faso & + & + & + & + & + & 5 \\
\hline 5. & (14) & DR Congo & + & + & + & + & + & 5 \\
\hline 6. & (15) & Ethiopia & - & + & + & + & + & 4 \\
\hline 7. & (16) & Zambia & - & + & + & + & + & 4 \\
\hline 8. & (17) & Ethiopia & - & + & + & + & + & 4 \\
\hline 9. & (18) & Ethiopia & + & + & + & + & + & 5 \\
\hline 10. & (19) & B/Faso & - & + & + & - & + & 3 \\
\hline 11. & (20) & Rwanda & - & + & + & + & + & 4 \\
\hline 12. & (21) & Ethiopia & + & + & + & + & + & 5 \\
\hline 13. & (22) & Nigeria & - & + & + & - & + & 3 \\
\hline 14. & (23) & Mozambique & - & + & + & - & + & 3 \\
\hline 15. & (24) & Ethiopia & + & + & + & + & + & 5 \\
\hline 16. & (25) & Nigeria & - & + & + & + & + & 4 \\
\hline 17. & (26) & Ethiopia & - & + & + & + & + & 5 \\
\hline 18. & (27) & Nigeria & - & + & + & + & + & 4 \\
\hline 19. & (28) & Nigeria & - & + & + & + & + & 4 \\
\hline 20. & (29) & Nigeria & + & + & + & + & + & 5 \\
\hline 21. & (30) & B/Faso & - & + & + & + & + & 4 \\
\hline 22. & (31) & Egypt & + & + & + & + & + & 5 \\
\hline 23. & (32) & Sudan & - & + & + & + & + & 4 \\
\hline 24. & (33) & Sao tome & - & + & + & + & + & 4 \\
\hline 25. & (34) & Nigeria & - & + & + & + & + & 4 \\
\hline 26. & (35) & Ivory cost & + & + & + & + & + & 5 \\
\hline 27. & (36) & Tanzania & - & + & + & + & + & 4 \\
\hline 28. & (37) & Cameroon & - & + & + & + & + & 4 \\
\hline 29. & (38) & Cameroon & - & + & + & + & + & 4 \\
\hline 30. & (39) & Nigeria & - & + & + & + & + & 4 \\
\hline 31. & $(40)$ & Benin & - & + & + & - & + & 3 \\
\hline 32. & (41) & $\mathrm{B} /$ Faso & - & + & + & - & + & 3 \\
\hline 33. & (42) & Nigeria & - & + & + & + & + & 4 \\
\hline 34. & (43) & Egypt & - & + & + & + & + & 3 \\
\hline
\end{tabular}

\section{Results}

3.1 Characteristics of the included studies and pooled prevalence of toxoplasmosis among the pregnant women

Of all the 14363 studies searched from the literature, 14299 studies were excluded based on duplicate, language other than English, title and abstract that are not relevant to the research question. Of the 64 abstracts assessed for eligibility, only 42 full-text articles were available and out of which 39 records were eligible for the systematic review and meta-analysis (Figure 1). Table 2 presents the included studies based on the country of the study, sample size, antibody detected (IgG, IgM or both), and estimated prevalence. The total number of pregnant women that participated in the included studies is 11986 . The highest number of included studies were from Ethiopia and Nigeria. Of all the included studies, 59\% used ELISA for serological detection of anti-toxoplasma antibodies among the pregnant women. All the included studies reported the $\mathrm{IgG}^{+}$anti-toxoplasma antibody while only 13 studies reported the prevalence of the $\operatorname{lgM}^{+}$antibodies and eight studies reported both $\operatorname{lgG}^{+}$and $\operatorname{lgM}^{+}$antibodies. Among all the included studies, the minimum sample size was 43 subjects from Ethiopia (24) and the maximum sample size was 781 subjects from Democratic Republic of Congo (14). The highest prevalence reported by the included studies was $88.6 \%$ by Endris et al (15) from Ethiopia and the lowest prevalence was $12.2 \%$ from Rwanda (20).

However, in this study, the weighted estimated prevalence of toxoplasmosis among the pregnant women is $47 \%$ $(95 \% \mathrm{Cl}=38.4 \%$ to $55.4 \%)$ using random-effect model (Figure 2.2). The review indicated a heterogeneity (Figure 2.1) among the included studies $\left(I^{2} 98.9 \%\right.$, $\mathrm{Q}=3,433, \mathrm{df}=38, \mathrm{P}<0.0001)$. Egger's test, 2.88 $(95 \% \mathrm{Cl}=-8.8 \%$ to $14.5 \%)$ revealed no publication bias 
Table 2. Characteristics of included studies based on screening method and overall prevalence for each country

\begin{tabular}{|c|c|c|c|c|c|c|c|c|}
\hline & Country & Subjects(n) & $\operatorname{lgG}+(\mathrm{n}, \%)$ & $\operatorname{lgM}+(n, \%)$ & $\operatorname{lgG}+$ and $\operatorname{lgM}+(\mathrm{n}, \%)$ & Overall prevalence & Method & References \\
\hline 1. & Benin & 211 & $113(53.6 \%)$ & -- & -- & $113(53.6 \%)$ & ELISA & (40) \\
\hline 2 & Benin & 283 & $85(30.0 \%)$ & $1(0.4 \%)$ & -- & $86(30.4 \%)$ & ELFA & (46) \\
\hline 3. & B/Faso & 336 & $85(25.3 \%)$ & - & - & $85(25.3 \%)$ & ELISA & (41) \\
\hline 4. & B/Faso & 316 & $98(31.1 \%)$ & - & - & $98(31.1 \%)$ & ELISA & (13) \\
\hline 5. & B/Faso & 182 & $37(20.3)$ & $7(3.8)$ & - & $44(24.2)$ & ELISA & (19) \\
\hline 6. & B/Faso & 348 & $121(34.7 \%)$ & - & - & $121(34.7 \%)$ & ELISA & (30) \\
\hline 7. & Cameroon & 110 & $69(62.7 \%)$ & -- & $3(2.7 \%)$ & $72(65.5 \%)$ & ELISA & (38) \\
\hline 8. & Cameroon & 327 & $254(77.7 \%)$ & - & $3(0.9 \%)$ & $257(78.6 \%)$ & ELISA & (37) \\
\hline 9. & DR Congo & 781 & $627(80.3 \%)$ & $17(4.4 \%)$ & - & $644(84.7 \%)$ & ELFA & (14) \\
\hline 10. & DRSTP & 499 & $375(75.2 \%)$ & - & - & $375(75.2 \%)$ & LAT & (33) \\
\hline 11. & Egypt & 323 & $209(64.7 \%)$ & - & $9(2.8 \%)$ & $218(67.6 \%)$ & ELFA & (31) \\
\hline 12. & Egypt & 693 & $209(30.2)$ & - & - & $209(30.2 \%)$ & ELFA & (43) \\
\hline 13. & Ethiopia & 232 & $191(82.3)$ & & $7(3.0)$ & 198(85.3) & ELISA & (11) \\
\hline 14. & Ethiopia & 384 & $71(18.5 \%)$ & - & - & $71(18.5 \%)$ & LAT & (12) \\
\hline 15. & Ethiopia & 385 & $341(88.6 \%)$ & -- & - & $341(88.6 \%)$ & LAT & (15) \\
\hline 16. & Ethiopia & 288 & $246(85.4 \%)$ & - & - & $246(85.4 \%)$ & LAT & (17) \\
\hline 17. & Ethiopia & 401 & $96(23.9 \%)$ & - & - & $96(23.9 \%)$ & EIA & (18) \\
\hline 18. & Ethiopia & 210 & $159(75.7 \%)$ & - & - & $159(75.7 \%)$ & LAT & (21) \\
\hline 19. & Ethiopia & 201 & $163(81.1 \%)$ & $5(2.5 \%)$ & - & $168(83.6 \%)$ & ELISA & (7) \\
\hline 20. & Ethiopia & 263 & $180(68.4 \%)$ & - & - & $180(68.4 \%)$ & LAT & (26) \\
\hline 21. & Ethiopia & 43 & $33(76.7 \%)$ & $4(9.3 \%)$ & - & $37(86.0 \%)$ & DAT & (24) \\
\hline 22. & Ghana & 93 & $35(37.6 \%)$ & -- & -- & $35(37.6 \%)$ & ELISA & (47) \\
\hline 23. & Ivory Coast & 385 & $226(58.7 \%)$ & -- & -- & $226(58.7 \%)$ & ELFA & (35) \\
\hline 24 & Morocco & 128 & $54(42.1 \%)$ & - & $5(3.9 \%)$ & $59(46.0 \%)$ & ELISA & (48) \\
\hline 25. & Mozambique & 150 & $27(18.0 \%)$ & $1(0.7 \%)$ & - & $28(18.7 \%)$ & ELISA & (23) \\
\hline 26. & Nigeria & 374 & $109(29.1 \%)$ & $3(0.8 \%)$ & - & $112(29.9 \%)$ & LAT & (34) \\
\hline 27. & Nigeria & 90 & $20(22.2 \%)$ & - & - & $20(22.2 \%)$ & ELISA & (22) \\
\hline 28. & Nigeria & 360 & $144(40.0 \%)$ & $26(7.2 \%)$ & $6(1.7 \%)$ & $176(48.9 \%)$ & ELISA & (44) \\
\hline 29. & Nigeria & 391 & $119(30.4 \%)$ & $67(17.1 \%)$ & - & $186(47.6 \%)$ & ELISA & (25) \\
\hline 30. & Nigeria & 173 & $48(27.7 \%)$ & - & - & $48(27.7 \%)$ & LAT & (27) \\
\hline 31. & Nigeria & 400 & $112(28.0 \%)$ & - & - & $112(28.0 \%)$ & ELISA & (28) \\
\hline 32. & Nigeria & 273 & $84(30.8 \%)$ & $9(3.3 \%)$ & - & $93(34.1 \%)$ & ELISA & (42) \\
\hline 33. & Nigeria & 377 & $135(35.8 \%)$ & - & - & $135(35.8 \%)$ & ELISA & (29) \\
\hline 34. & Nigeria & 288 & $123(42.4 \%)$ & $33(11.5 \%)$ & $33(11.5)$ & $189(65.6 \%)$ & ELISA & (39) \\
\hline 35. & Rwanda & 384 & $37(9.6 \%)$ & $10(2.6 \%)$ & - & $47(12.2 \%)$ & ELISA & (20) \\
\hline 36. & Sudan & 487 & $166(34.1 \%)$ & - & - & $166(34.1 \%)$ & ELISA & (32) \\
\hline
\end{tabular}

Note: $\mathrm{n}=$ number, \%=percentage

$(P=0.619)$ to influence the pooled estimate of toxoplasmosis.

\subsection{Prevalence of toxoplasmosis among pregnant women in different trimesters}

Some of the included study reported the stratification of the participants based the trimester. From 23 studies, 3508 pregnant women were within the first trimester. Twenty-one studies had 1367 participants in second trimester while 20 studies had 1351 participants in third trimester. The pooled prevalence of toxoplasmosis for each category of trimester stage was estimated using the random effect analysis. The pooled prevalence estimates for toxoplasmosis among pregnant women in first trimester was $29.0 \%(95 \% \mathrm{Cl}=17.0 \%-42.0 \%)$ the $I^{2}$ test indicated high heterogeneity $\left(I^{2} 98.6 \% Q=1,551\right.$, $d f=22, P<0.0001$ ) (Figure $4 A$ and $5 A$ ). The pooled prevalence estimates for toxoplasmosis among pregnant women in second trimester was $35.0 \%(95 \% \mathrm{Cl}=27 \%$ $43 \%)$ the $I^{2}$ test indicated high heterogeneity $\left(I^{2} 95.9 \%\right.$ $Q=536, d f=20, P<0.0001$ ) (Figure 3.1 and 3.2). The pooled prevalence estimates for toxoplasmosis among pregnant women in the third trimester was $30.9 \%(95 \% \mathrm{Cl}=22 \%$ $41 \%)$ the $I^{2}$ test indicated high heterogeneity $\left(I^{2} 97.5 \%\right.$ $\mathrm{Q}=869, \mathrm{df}=19, \mathrm{P}<0.0001$ ) (Figure 3.1 and 3.2 ). 


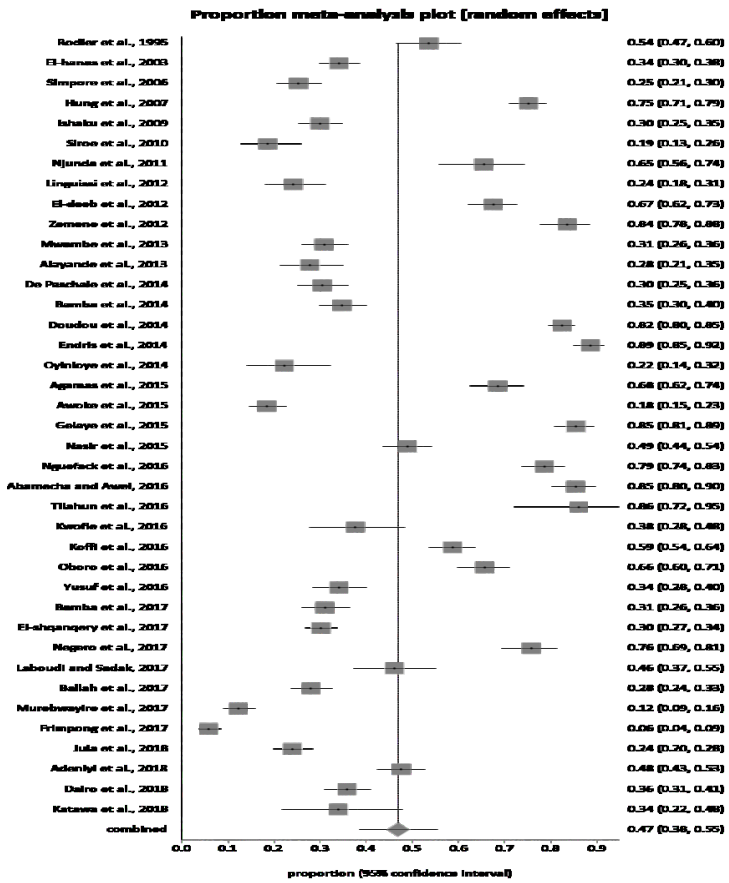

Figure 2.1. Forest plot diagram showing the overall seroprevalence of toxoplasmosis among pregnant women in Africa.

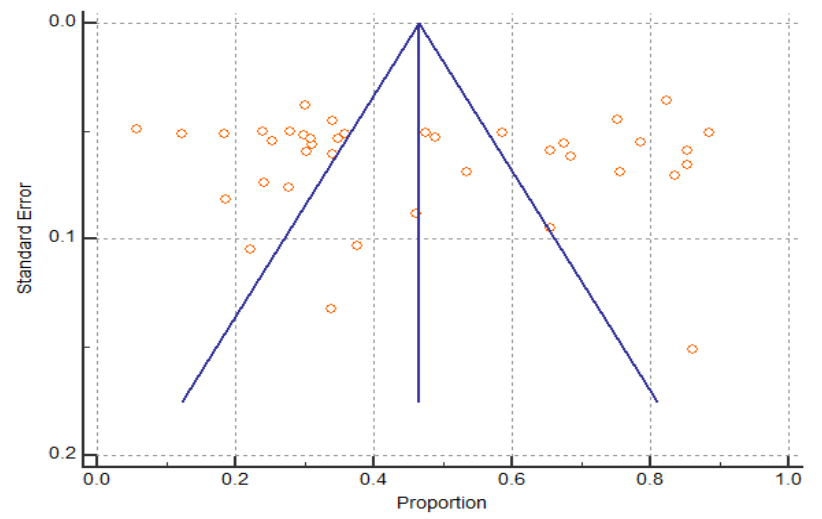

Figure 2.2. Funnel plot indicating the heterogeneity of the included studies

\subsection{Prevalence of toxoplasmosis among pregnant} women with history of association with cats

This study assessed the possible risk of exposure to cats focusing on either close contact with cats or ownership of cats. Only nine studies reported 629 pregnant women with history of contact with cats and has a pooled prevalence of toxoplasmosis of $50 \%$ (95\% Cl= $35 \%$ to $66 \%$ ). Heterogeneity among the studies was assessed to be high with $I^{2}=96.7 \%$ (95\% $\mathrm{Cl}=95.6 \%$ to $97.4 \%, \mathrm{Q}=240.4, \mathrm{df}=8, \mathrm{P}<0.0001$ ) Figure 4 . For the cat ownership, only 15 studies among the included studies reported the risk of toxoplasmosis among the pregnant that own cats. From these studies, the total number of pregnant women that owns cats is 765. The pooled prevalence of toxoplasmosis among the pregnant women with history of cat ownership is $26.2 \%(95 \% \mathrm{Cl}=17.9 \%$ to $35.5 \%)$. The studies showed high heterogeneity $\left(I^{2}=96.7 \%(95 \% \mathrm{Cl}=96.0 \%\right.$ to $97.3 \%$,
$\mathrm{Q}=427, \mathrm{df}=14, \mathrm{P}<0.0001)$ Figure 4.1 and 4.2 .

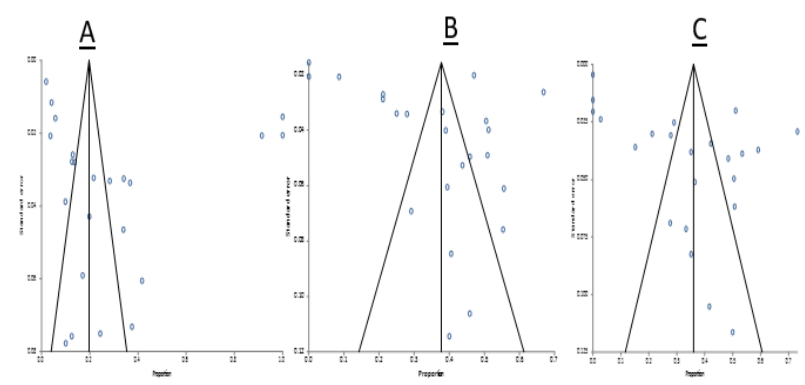

Figure 3.1. Funnel plots indicating the heterogeneity of the primary studies in different trimesters

3.4 Prevalence of toxoplasmosis among pregnant women with history of consumption of raw or poorly cooked meat

This review determined the pooled prevalence of toxoplasmosis related to consumption of raw or poorly cooked meat as reported by 19 primary studies among pregnant women. One thousand two hundred and forty pregnant women that were reported to be reactive to anti-toxoplasma antibody had history of consumption of raw or poorly cooked meat. The pooled prevalence of toxoplasmosis in this group of pregnant women is $43.3 \%(95 \% \mathrm{Cl}=30 \%$ to $50 \%)$. There is a high heterogeneity among the studies with $l^{2}=98.7 \%(95 \% \mathrm{Cl}=98.5 \%$ to $98.8 \%, Q=1381, d f=18, P<0.0001)$ Figure 5 .

\subsection{Discussion}

Toxoplasmosis in pregnancy can have a devastating consequence during pregnancy period on the fetus, the newborn and in later stage of life. Reports indicated that prevalence of toxoplasmosis among pregnant women in Africa ranges from $25.3 \%$ to $75.2 \%$ (6). This is probably due to the endemicity of the infection because of the climatic and environmental conditions suitable for the survival of the $T$. gondii oocyst and availability of the transmission vehicles as well as lack of proper preventive policies in many of the African cities. In view of the forgoing, this review identified studies that reported seroprevalence studies from different parts of Africa. Thirty-nine eligible studies were obtained from available databases such as Google Scholar, ScienceDirect, Scopus, and PubMed. Eleven thousand nine hundred and eighty-six (11986) pregnant women participated in the eligible studies out of which 5347 were IgG reactive that accounts for $44.5 \%$ prevalence. This finding is higher than $36.5 \%$ reported by Bigno et al (49) which may probably be due to differences in inclusion and exclusion criteria for both reviews. The stratification of the pregnant women based on gestational age was reported by some of the eligible studies to include 3508 pregnant women in first trimester, 1367 in the second trimester and 1351 in the third trimester. The risk of transplacental transmission 
a.

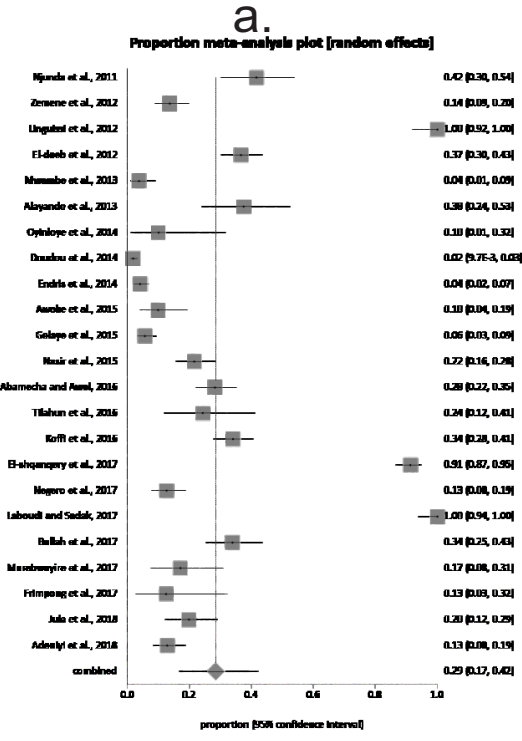

b.

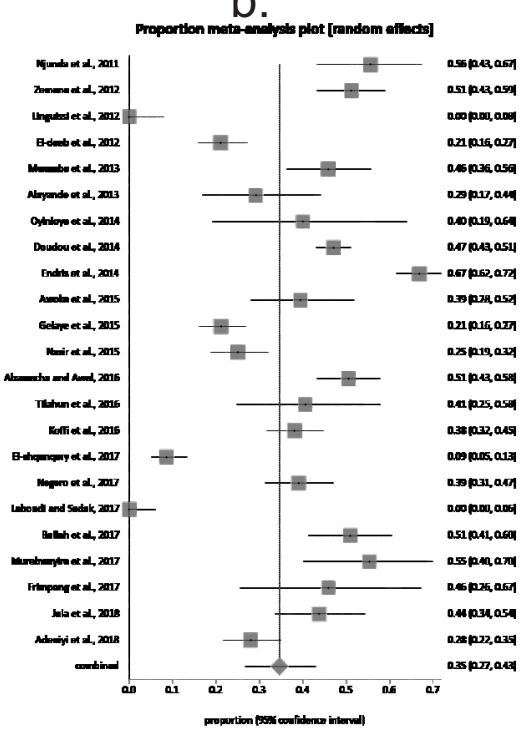

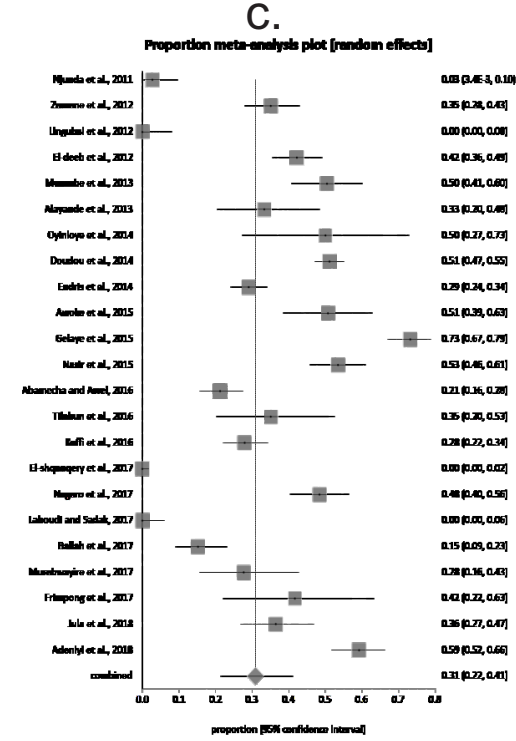

Figure 3.2. Forest plot diagram showing the overall seroprevalence of toxoplasmosis among pregnant women in (a) First trimester, (b) Second trimester and (c) Third trimester.
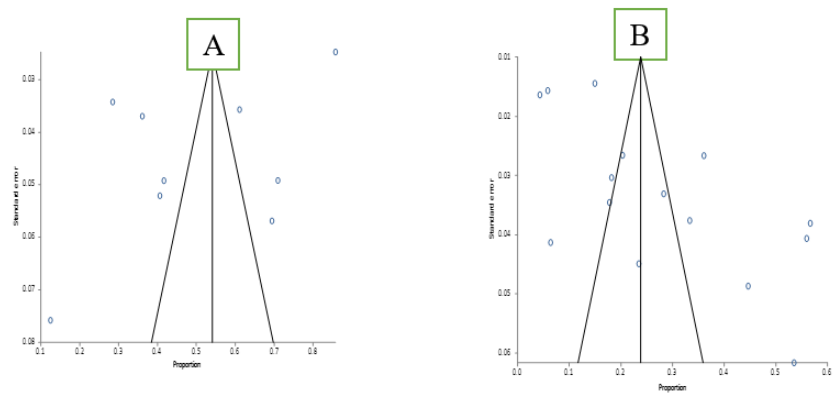

Figure 4.1. Funnel plots for cat contact (A) and cat ownership (B)

of $T$. gondii is more pronounced in the third trimester because of the maturity of the placenta and low immunity $(6,50)$.

Risk factors of toxoplasmosis are many but may differ from one region to another which reflects on the variation in prevalence between and within localities. Cats, being the definitive hosts of $T$. gondii, spread the oocyst along with feces to contaminate soil, water, and food substances that become the source of infection to humans (51). Thus, many studies reported that cat ownership, contact with cats as well as handling cat litter boxes are associated with $T$. gondii infection $(3,28,42,52)$. Although contact with cats is commonly disputed as a direct risk of infection (53), the risk is higher among those that had history of close contact with cats, which may be related to handling of cat litters $(54,55)$. Again, contact with contaminated soil $(56)$ with T. gondii oocyst as detected in many of schools play grounds (57) may result in childhood toxoplasmosis (58) as well as infection in pregnancy among women with history of ingestion of soil (59).

In this review, 629 pregnant women were reported by nine studies to have history of close contact with cats.
The pooled prevalence of toxoplasmosis among these pregnant women was $50.3 \%(95 \% \mathrm{Cl}=35 \%$ to $66 \%$ ). Furthermore, 15 studies reported 765 pregnant women who had history of cat ownership with pooled prevalence of toxoplasmosis at $26.2 \%$ (18\% to $36 \%$ ). In these two cases, it appears that the pooled prevalence among those with history of close contact with cats doubles the prevalence of toxoplasmosis among those with history of cat ownership. For all the two risks of contracting toxoplasmosis, the transmission of the infection is via the contact with cat litters (53) or contaminated soil that further contaminates vegetables, fruits, and water that were reported to be the sources of infection $(52,59,60)$. Therefore, the habits of handling cat litters and soil should be of concern among pregnant women to ensure prevention of infection transmission and that adequate information on the longevity of the oocyst in the environment and its mode of dispersals should be disseminated to pregnant women at least during antenatal period.

The tissue cyst embedded in the meat of most intermediate hosts such as the sheep, goats, cattle, pigs, and many other food animals including chickens, harbors a slowly replicating bradyzoite that reactivates to a rapidly invasive tachyzoite (2). Thus, ingestion of raw or poorly cooked meat that harbors the tissue cysts has an attendant risk of contracting the infection (51). Increase in consumption of meat and preference were reported to differ between communities $(7,61,62)$. High prevalence of toxoplasmosis has been detected among food animals and poultry from different countries in Africa $(63,64,65,66)$. The prevalence of toxoplasmosis among food animals poses a risk of zoonotic transmission to humans if their meat products are poorly processed or consumed in raw form. Thus, pregnant 
a.

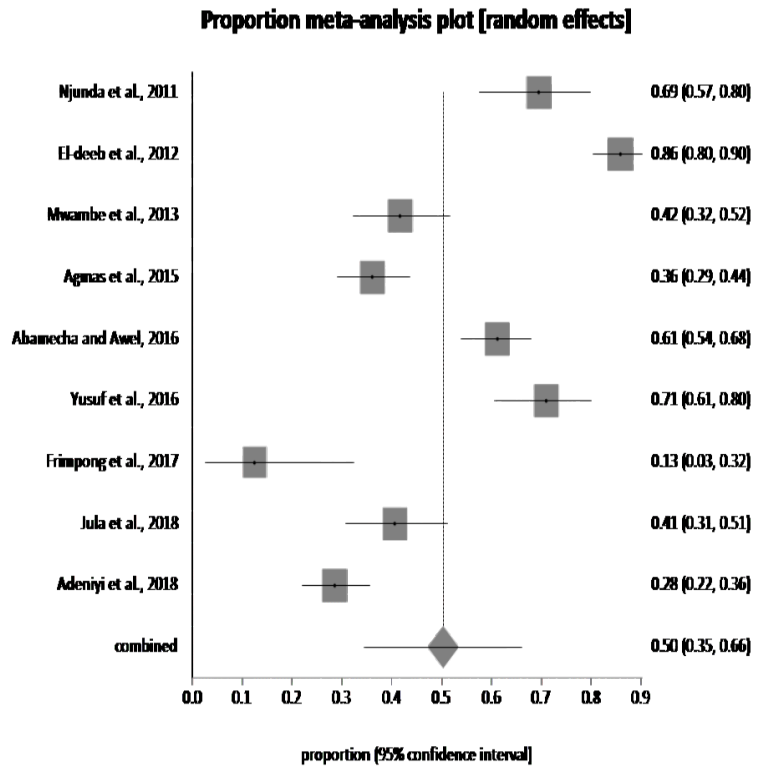

Figure 4.2. Forest plots for cat contact (A) and cat ownership (B)

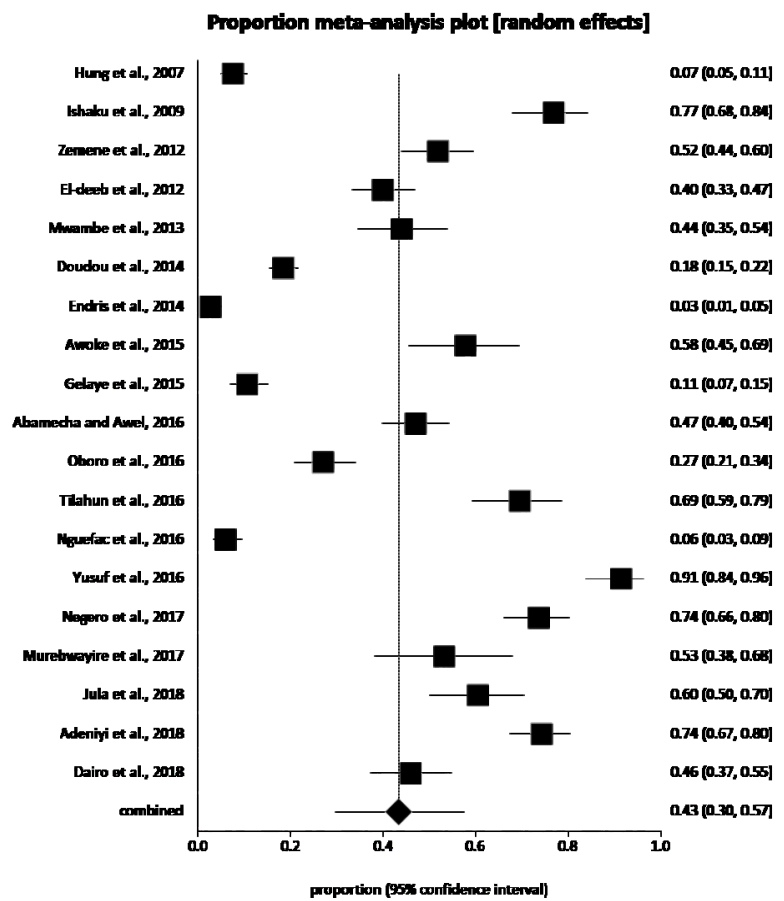

Figure 5. Forest plot showing the pooled prevalence of toxoplasmosis among subjects with history of consumption of raw or poorly cooked meat b.

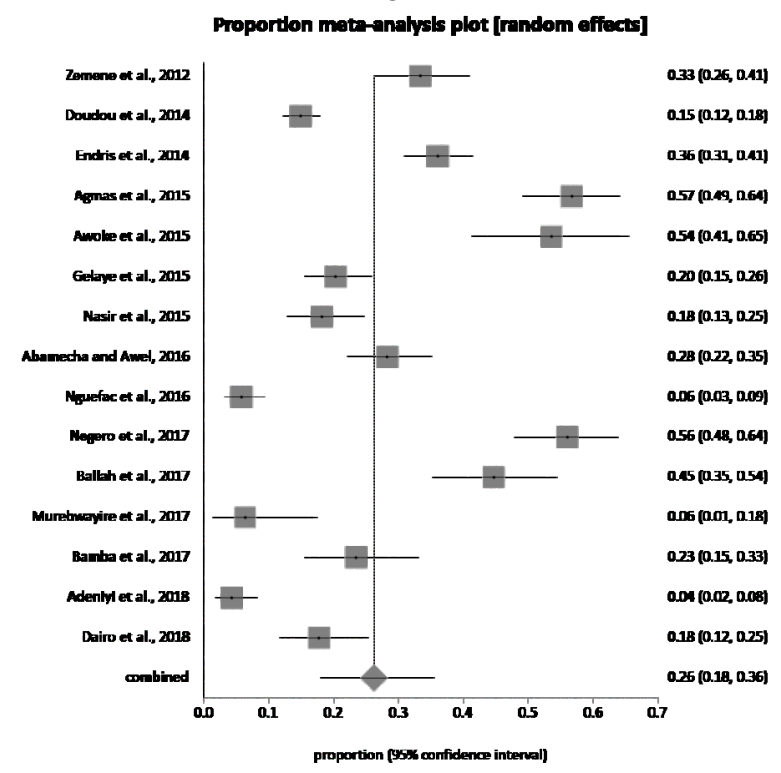

women with history of consuming raw meat as a culture in some parts of Africa (11) or poorly cooked meat are at higher risk of getting the infection. In this review, however, 1240 pregnant women reported to have history of consumption of raw or poorly cooked meat had $43.3 \%(95 \% \mathrm{Cl}=30 \%$ to $50 \%)$ pooled prevalence of toxoplasmosis.

Even though many other studies disputed the possibilities of transmitting the infection through meat consumption despite taken it raw or poorly cooked $(7,67,68)$ other studies reported strong association between meat consumption and toxoplasmosis across the globe (32). For the fact that meat sourced from food animals can harbor a tissue cyst, its availability for transmission depends on several factors that differ from one community to another which include the cultural differences, eating habits, meat of preference, and purchasing capability $(16,69)$. More interestingly, however, outbreak of toxoplasmosis was reported to be associated with consumption of raw or poorly cooked meat from pig, mutton, lamb and beef $(70,71)$.

Although, the greater the severity of sequelae of toxoplasmosis in the fetus or newborn points at earlier transmission during gestation, transmission during the

Table 3. Pooled prevalence in different trimesters and risk factors of toxoplasmosis

\begin{tabular}{|c|c|c|c|c|c|c|c|c|}
\hline Category & No. of studies & Prevalence $(95 \% \mathrm{Cl})$ & $12 \%(95 \% \mathrm{Cl})$ & Hetero & yeneity test & Egger & istest & \\
\hline & & & & $Q$ & $P$ & $\mathrm{t}$ & $P$ & \\
\hline $1^{\text {st t trimester }}$ & 23 & $29.0(17-42)$ & $98.6 \%(98.4-98.7)$ & 1551 & $<0.0001$ & 8.25 & 0.151 & \\
\hline $2^{\text {nd }}$ trimester & 21 & $35.0(26-43)$ & $95.9 \%(95.1-96.5)$ & 536 & $<0.0001$ & 7.50 & 0.015 & \\
\hline $3^{\text {rd }}$ trimester & 20 & $30.9(22-41)$ & $97.5 \%(97.1-97.8)$ & 869 & $<0.0001$ & 9.70 & $<0.0001$ & \\
\hline Cat contact & 9 & $50.3(35-66)$ & $96.7 \%(95.6-97.4)$ & 240 & $<0.0001$ & -9.95 & 0.149 & \\
\hline Cat ownership & 15 & $26.2(18-36)$ & $96.7 \%(96.0-97.3)$ & 427 & $<0.0001$ & 9.81 & 0.0019 & "consumption of poorly \\
\hline "Meat & 19 & $43.3(30-50)$ & $98.7 \%(98.5-98.8)$ & 1381 & $<0.0001$ & 8.53 & 0.0021 & $\begin{array}{l}\text { or raw meat, } \mathrm{Q}=\text { Cochran } \\
\mathrm{P}=\mathrm{p} \text { values }\end{array}$ \\
\hline
\end{tabular}


late gestational period is associated mainly to alteration of the function of the immune cells with majority of the neonates appearing normal at birth (50). The efficiency of placenta as a natural barrier to infection is more pronounced during the first trimester that resulted in minimal cases but with heavy consequences on the fetus (2). Major abnormalities include abortion, hydrocephalus, deafness, seizures, mental retardation and sensory and motor abnormalities. Congenital infection involving the retina may present with microphthalmia, strabismus, cataract, optic neuritis, uveitis, retinochoroiditis, and retinal necrosis that may lead to blindness.

\subsection{Conclusion}

Findings of this systematic review and meta-analysis indicate that toxoplasmosis is highly prevalent in African countries with no adequate measures to halt its spread. Effective screening of mothers and neonate is necessary to prevent mother to child transmission and to halt progression of the disease among the new born to prevent development of late sequelae in later life. Hence, more effort should be made to disseminate information focusing on risk factors and prevention strategies for control of the disease especially among pregnant women, children and immunocompromised patients.

\section{Source of Funding \\ None provided}

\section{Declaration of competing interest}

Authors declared that there is no competing interest

\section{References}

1. Flegr J, Prandota J, Sovičková M, Israili ZH. Toxoplasmosis-a global threat. Correlation of latent toxoplasmosis with specific disease burden in a set of 88 countries. PloS one 2014; 9(3): e90203.

2. Robert-Gangneux, F., \& Dardé, M. L. Epidemiology of and diagnostic strategies for toxoplasmosis. Clinical microbiology reviews 2012; 25(2), 264-296.

3. McAuley JB. Congenital toxoplasmosis. Journal of the Pediatric Infectious Diseases Society 2014; 3:S30-5.

4. Ahmadpour E, Daryani A, Sharif M, Sarvi S, Aarabi M, Mizani A Rahimi MT, Shokri A. Toxoplasmosis in immunocompromised patients in Iran: a systematic review and meta-analysis. The Journal of Infection in Developing Countries 2014; 8(12):1503-10.

5. Saki J, Shafieenia S, Foroutan-Rad M. Seroprevalence of toxoplasmosis in diabetic pregnant women in southwestern of Iran. Journal of Parasitic Diseases 2016; 40(4):1586-9.

6. Foroutan-Rad M, Majidiani H, Dalvand S, Daryani A, Kooti W, Saki J, Hedayati-Rad F, Ahmadpour E. Toxoplasmosis in blood donors: a systematic review and meta-analysis. Transfusion Medicine Reviews 2016; 30(3):116-22.

7. Zemene E, Yewhalaw D, Abera S, Belay T, Samuel A, Zeynudin A Seroprevalence of Toxoplasma gondii and associated risk factors among pregnant women in Jimma town, Southwestern Ethiopia. BMC Infectious Diseases 2012; 12(1):1-6.

8. Montoya, J.G. and Liesenfeld, O. Toxoplasmosis. Lancet 2004 363: 1965-1976

9. Pfaff AW, Abou-Bacar A, Letscher-Bru V, Villard O, Senegas A,
Mousli M, Candolfi E. Cellular and molecular physiopathology of congenital toxoplasmosis: the dual role of IFN- $\gamma$. Parasitology 2007:134(13):1895-902.

10. Herzog R, Álvarez-Pasquin MJ, Díaz C, Del Barrio JL, Estrada JM, Gil Á. Are healthcare workers' intentions to vaccinate related to their knowledge, beliefs and attitudes? A systematic review. BMC Public Health 2013; 13(1):1-7.

11. Abamecha, F., Awel, H. Seroprevalence and risk factors of Toxo plasma gondii infection in pregnant women following antenatal care at Mizan Aman General Hospital, Bench Maji Zone (BMZ), Ethiopia. BMC Infectious Diseases 2016; 16: 1-8

12. Awoke K, Nibret E, Munshea A. Sero-prevalence and associated risk factors of Toxoplasma gondii infection among pregnant women attending antenatal care at Felege Hiwot Referral Hospital, Northwest Ethiopia. Asian Pacific Journal of Tropical Medicine 2015; 8(7):549-54.

13. Bamba $S$, Cissé M, Sangaré I, Zida A, Ouattara $S$, Guiguemdé RT. Seroprevalence and risk factors of Toxoplasma gondii infection in pregnant women from Bobo Dioulasso, Burkina Faso. BMC Infectious Diseases 2017; 17(1):1-6

14. Doudou $Y$, Renaud $P$, Jacqueline $F$, Hypolite $S$, Hypolite $M$, Patrick $M$ Andreia ID, Van Sprundel M, Marleen B, Van Geertruyden JP, Pascal L. Toxoplasmosis among pregnant women: high seroprevalence and risk factors in Kinshasa, Democratic Republic of Congo. Asian Pacific Journal of Tropical Biomedicine 2014; 4(1):69-74.

15. Endris M, Belyhun Y, Moges F, Adefiris M, Tekeste Z, Mulu A Kassu A. Seroprevalence and associated risk factors of Toxoplasma gondii in pregnant women attending in Northwest Ethiopia. Iranian Journal of Parasitology 2014; 9(3):407.

16. Frimpong C, Makasa M, Sitali L, Michelo C. Seroprevalence and determinants of toxoplasmosis in pregnant women attending antenatal clinic at the university teaching hospital, Lusaka, Zambia. BMC Infectious Diseases 2017; 17(1):1-8

17. Gyang VP, Akinwale OP, Lee YL, Chuang TW, Orok A, Ajibaye $O$, Liao CW, Cheng PC, Chou CM, Huang YC, Fan KH. Toxoplasma gondii infection: seroprevalence and associated risk factors among primary schoolchildren in Lagos City, Southern Nigeria. Revista da Sociedade Brasileira de Medicina Tropical 2015; 48 : 56-63

18. Jula J, Girones G, Edao B, Deme C, Cebrian J, Butrón L, Reyes F Ramos JM. Seroprevalence of Toxoplasma gondii infection in pregnant women attending antenatal care in southern Ethiopia. Revista Española de Quimioterapia 2018; 31(4):363.

19. Linguissi LS, Nagalo BM, Bisseye C, Kagoné TS, Sanou M, Tao I, Benao V, Simporé J, Koné B. Seroprevalence of toxoplasmosis and rubella in pregnant women attending antenatal private clinic at Ouagadougou, Burkina Faso. Asian Pacific Journal of Tropical Medicine 2012; 5(10):810-3.

20. Murebwayire E, Njanaake K, Ngabonziza JC, Jaoko W, Njunwa KJ. Seroprevalence and risk factors of Toxoplasma gondii infection among pregnant women attending antenatal care in Kigali, Rwanda. Tanzania Journal of Health Research 2017; 19(1):20-25.

21. Negero J, Yohannes M, Woldemichael K, Tegegne D. Seroprevalence and potential risk factors of $T$. gondii infection in pregnant women attending antenatal care at Bonga Hospital, Southwestern Ethiopia. International Journal of Infectious Diseases 2017; 57 44-9.

22. Oyinloye SO, Igila-Atsibee M, Ajayi B, Lawan MA. Serological screening for ante-natal toxoplasmosis in Maiduguri municipa council, Borno state, Nigeria. African Journal of Clinical and Experimental Microbiology 2014; 15(2):91-6.

23. Sitoe SP, Rafael B, Meireles LR, Andrade Jr HF, Thompson R. Preliminary report of HIV and Toxoplasma gondii occurrence in pregnant women from Mozambique. Revista do Instituto de Medicina Tropical de São Paulo 2010; 52:291-5

24. Tilahun B, Hailu Y, Tilahun G, Ashenafi H, Vitale M, Di Marco V Gebremedhin EZ. Seroprevalence and risk factors of Toxoplasma gondii infection in humans in East Hararghe Zone, Ethiopia. Epidemiology \& Infection 2016; 144(1):64-71

25. Adeniyi OT, Adekola SS, Oladipo OM. Seroepidemiology of toxoplasmosis among pregnant women in Osogbo, Southwestern Nigeria. Journal of Infectious Diseases and Immunity 2018; 10(2) 8-16. 
26. Agmas B, Tesfaye R, Koye DN. Seroprevalence of Toxoplasma gondii infection and associated risk factors among pregnant women in Debre Tabor, Northwest Ethiopia. BMC Research Notes 2015; 8(1):1-7.

27. Alayande MO, Edungbola LD, Fabiyi JP, Awosan KJ. Occurrence of antibody to Toxoplasma infection among pregnant women with obstetric histories and at different trimesters in Sokoto, Northwest Nigeria. American Journal of Research Communication 2013; 1(9):240-7

28. Ballah FM, Maikai BV, Magaji AA, Shuaibu AB, El-Nafaty AU, Sambo YT, Auwal AA, Faruk HU, Suleiman F. Seroprevalence and risk of Toxoplasma gondii infection among pregnant women at Federal Teaching Hospital Gombe, Nigeria. Asian Journal of Medicine and Health 2017; 17:1-5

29. Dairo MD, Ogunjimi T, Ayinmode AB. Knowledge, risk factors and prevalence of toxoplasmosis among pregnant women at primary health care level in Ibadan, Southwestern Nigeria. African Journal of Biomedical Research 2018; 21(3):267-71.

30. Bamba S, Sourabie Y, Guiguemde TR, Karou DS, Simpore J, Bambara M, Villena I. Seroprevalence of latent Toxoplasma gondii infection among HIV-infected pregnant women in Bobo-Dioulasso Burkina Faso. Pakistan Journal of Biological Sciences 2014; 17(9): 1074-8.

31. El Deeb HK, Salah-Eldin H, Khodeer S, Allah AA. Prevalence of Toxoplasma gondii infection in antenatal population in Menoufia governorate, Egypt. Acta Tropica 2012; 124(3):185-91.

32. Elnahas A, Gerais AS, Elbashir MI, Eldien ES, Adam I. Toxoplasmosis in pregnant Sudanese women. Saudi Medical Journal 2003 24(8):868-70.

33. Hung CC, Fan CK, Su KE, Sung FC, Chiou HY, Gil V, Ferreira MD de Carvalho JM, Cruz C, Lin YK, Tseng LF. Serological screening and toxoplasmosis exposure factors among pregnant women in the Democratic Republic of Sao Tome and Principe. Transactions of the Royal Society of Tropical Medicine and Hygiene 2007, 101(2):134-9.

34. Ishaku B, Ajogi I, Umoh JU, Lawal I, Randawa AJ. Seroprevalence and risk factors for Toxoplasma gondii infection among antenata women in Zaria, Nigeria. Research Journal of Medicine and Medical Sciences 2009;4(2):483-8.

35. Koffi M, Konaté I, Sokouri DP, Konan T, Ahouty B, Bosso JC Seroepidemiology of Toxoplasmosis in Pregnant Women Attending Antenatal Clinics at the Center for Maternal and Child Health Care in Daloa in Ivory Coast. International Journal of Tropical Disease \& Health 2015; 14(33):125-32.

36. Mwambe B, Mshana SE, Kidenya BR, Massinde AN, Mazigo HD, Michael D, Majinge C, Groß U. Sero-prevalence and factors associated with Toxoplasma gondii infection among pregnant women attending antenatal care in Mwanza, Tanzania. Parasites \& Vectors 2013; 6(1):1-5.

37. Nguefack CT, Meumeu IK, Ngaba GP, Kongnyuy E, Njamen TN. Prevalence and Factors Associated with Toxoplasma gondi Immunization among Pregnant Women in Douala-Cameroon. Journal of Womens Health, Issues Care 2016; 5(6):2.

38. Njunda AL, Nsagha DS, Assob JN, Kamga HF, Tafili RT, Achidi EA Seroepidemiology of toxoplasmosis in pregnant women attending the University Teaching Hospital in Yaounde, Cameroon. Inter national Journal of Health Research 2011; 4(1):1-9.

39. Oboro IL, Ozumba UC, Obunge OK. Recent Toxoplasmosis among Pregnant Women Receiving Antenatal Care at the University of Port Harcourt Teaching Hospital, Nigeria. International Journal Of Tropical Disease \& Health 2016; 2(4):1-7.

40. Rodier MH, Berthonneau J, Bourgoin A, Giraudeau G, Agius G Burucoa C, Hekpazo A, Jacquemin JL. Seroprevalences of Toxo plasma, malaria, rubella, cytomegalovirus, HIV and treponemal infections among pregnant women in Cotonou, Republic of Benin. Acta tropica 1995;59(4):271-7.

41. Simpore J, Savadogo A, Ilboudo D, Nadambega MC, Esposito M Yara J, Pignatelli S, Pietra V, Musumeci S. Toxoplasma gondii, $\mathrm{HCV}$, and HBV seroprevalence and co-infection among HIV positive and-negative pregnant women in Burkina Faso. Journal of Medical Virology. 2006;78(6):730-3.

42. Yusuf AM, Yahaya S, Azeez-Akande O. Seroprevalence and risk factors of Toxoplasma gondii infection (toxoplasmosis) among
HIV seropositive pregnant women in a tertiary healthcare centre Kano, Northern Nigeria. Journal Medicine Medical Sciences 2016; 7:001-5.

43. El-Shqanqery $\mathrm{HE}$, Ibrahim $\mathrm{HM}$, Mohamed $\mathrm{AH}$, El-Sharaawy AA Seroprevalence of Toxoplasma gondii infection and associated risk factors among asymptomatic pregnant females in Egypt. Journal of the Egyptian Society of Parasitology 2017; 47(1):93-100

44. Nasir IA, Aderinsayo $\mathrm{AH}$, Mele HU, Aliyu MM. Prevalence and associated risk factors of Toxoplasma gondii antibodies among pregnant women attending Maiduguri teaching hospital, Nigeria. Journal of Medical Sciences 2015;15(3):147.

45. Katawa G, Kolou M, Nadjir LK, Ataba E, Bomboma G, Karou SD CD4 T-lymphocytes count in HIV-Toxoplasma gondii co-infected pregnant women undergoing a prevention of mother-to-child transmission program. Journal of Biosciences and Medicines 2018; 6(04):76.

46. De Paschale $M$, Ceriani $C$, Cerulli T, Cagnin D, Cavallari S, Cianflone $A$, Diombo K, Ndayaké J, Aouanou G, Zaongo D, Priuli G. Antenata screening for Toxoplasma gondii, Cytomegalovirus, Rubella and Treponema pallidum infections in Northern Benin. Tropical Medicine \& International Health 2014; 19(6):743-6.

47. Kwofie KD, Ghansah A, Osei JH, Frempong KK, Obed S, Frimpong $\mathrm{EH}$, Boakye DA, Suzuki T, Ohta N, Ayi I. Indication of risk of motherto-child Toxoplasma gondii transmission in the Greater Accra Region of Ghana. Maternal and Child Health Journal 2016; 20(12): 2581-8.

48. Laboudi M, Sadak A. Serodiagnosis of toxoplasmosis: the effect of measurement of IgG avidity in pregnant women in Rabat in Morocco. Acta Tropica 2017:172:139-42.

49. Bigna JJ, Tochie JN, Tounouga DN, Bekolo AO, Ymele NS, Youda EL, Sime PS, Nansseu JR. Global, regional, and country seroprevalence of Toxoplasma gondii in pregnant women: a systematic review, modelling and meta-analysis. Scientific Reports 2020 10(1):1-0.

50. Avelino MM, Campos Júnior D, Parada JB, Castro AM. Risk factors for Toxoplasma gondii infection in women of childbearing age. Brazilian Journal of Infectious Diseases 2004 ;8(2):164-74

51. Sharif AA, Aliyu M, Yusuf MA, Getso MI, Yahaya $H$, Bala JA, Yusuf I, Wana MN. Risk factors and mode of transmission of toxoplasmosis in Nigeria: a review. Bayero Journal of Pure and Applied Sciences 2018; 11(2):107-21.

52. Ibrahim A, Kumurya AS, Yahaya H, Abdu A, Ado BK, Ella EE, Suleiman AB, Sulaiman MA, Aminu MA, Koki AY. T-cell mediated immune responses in obstetric population acutely infected with toxoplasmosis in Kano, Nigeria. UMYU Journal of Microbiology Research 2017; 2(1):217-27.

53. Elsheikha HM. Congenital toxoplasmosis: priorities for further health promotion action. Public Health 2008; 122(4):335-53.

54. Nissapatorn V, Suwanrath $C$, Sawangjaroen $N$, Ling $L Y$, Chandeying V. Toxoplasmosis-serological evidence and associated risk factors among pregnant women in southern Thailand. The American Journal of Tropical Medicine and Hygiene 2011; 85(2):243

55. Shao ER, Ndazana SG, Chacha W, Masenga G, Tolbert S, Mosha D, Kifaro EG, Nyombi BM. Annals of Clinical and Laboratory Research 2015; 3(2):17.

56. Weigel RM, Dubey JP, Dyer D, Siegel AM. Risk factors for infection with Toxoplasma gondii for residents and workers on swine farms in Illinois. The American Journal of Tropical Medicine and Hygiene 1999; 60(5):793-8.

57. dos Santos TR, Nunes CM, Luvizotto MC, de Moura AB, Lopes WD da Costa AJ, Bresciani KD. Detection of Toxoplasma gondii oocysts in environmental samples from public schools. Veterinary Parasitology 2010; 171(1-2):53-7.

58. Gyang VP, Akinwale OP, Lee YL, Chuang TW, Orok A, Ajibaye $O$ Liao CW, Cheng PC, Chou CM, Huang YC, Fan KH. Toxoplasma gondii infection: seroprevalence and associated risk factors among primary schoolchildren in Lagos City, Southern Nigeria. Revista da Sociedade Brasileira de Medicina Tropical 2015;48:56-63.

59. Yohanes T, Zerdo Z, Chufamo N, Abossie A. Seroprevalence and Associated Factors of Toxoplasma gondii Infection among Pregnant Women Attending in Antenatal Clinic of Arba Minch Hospital, South Ethiopia: Cross-Sectional Study. Translational Biomedicine 2017; 8(1):105 
60. Olajubu FA, Osinupebi OA, Deji-Agboola M, Jagun EO. Seropre valence of HIV among blood donors, antenatal women and other patients in a tertiary hospital in Nigeria. Brazilian Journal of Infectious Diseases 2009; 13(4):280-3.

61. Bénard C, Bonnet B, Guibert B. Demand for farm animal products in Nigeria: An opportunity for Sahel countries. Grain de Sel 2010; 51(1):14-5.

62. Adetunji MO, Rauf MO. Analysis of household demand for meat in southwest, Nigeria. Global Journal of Science Frontier Research 2012;12(1).

63. Gambo BG, Raufu IA, Ambali AG. Residents in Borno State and their meat preference among ruminant species. African Journal of General Agriculture 2010; 6(2):53-8.

64. Ahemen T, Zahraddeen D. Species contribution as source of meat and their foetal wastage in Taraba State, Nigeria. Archives of Applied Science Research 2010; 2(5):85-91.

65. Kamani J, Mani AU, Egwu GO. Seroprevalence of Toxoplasma gondii infection in domestic sheep and goats in Borno state, Nigeria. Tropical Animal Health and Production 2010 ;42(4):793-7.
66. Onyiche TE, Ademola IO. Seroprevalence of anti-Toxoplasma gondii antibodies in cattle and pigs in Ibadan, Nigeria. Journal of Parasitic Diseases 2015; 39(2):309-14.

67. Ertug S, Okyay P, Turkmen M, Yuksel H. Seroprevalence and risk factors for Toxoplasma infection among pregnant women in Aydin province, Turkey. BMC Public Health 2005 ;5(1):1-6.

68. Nijem, K.I., Al-Amleh, S. Seroprevalence and associated risk factors of toxoplasmosis in pregnant women in Hebron district, Palestine. Eastern Mediterranian Health Journal 2009; 15:1278 $-1284$

69. Hussain MA, Stitt V, Szabo EA, Nelan B. Toxoplasma gondii in the Food Supply $2017 ; 6(2): 21-25$

60. Choi WY, Nam HW, Kwak NH, Huh W, Kim YR, Kang MW, Cho SY, Dubey JP. Foodborne outbreaks of human toxoplasmosis. Journal of Infectious Diseases 1997; 175(5):1280-2.

71. Adeela, A., Azhar, M., Muhammad, F.Q., Kamran, A., Aftab, A.A. Detection of Toxoplasma gondii in environmental matrices (water, soil, fruits and vegetables). African Journal Microbiology Research 2013; 7:1505-1511. 